Original Research Article

\title{
A study of prescription pattern of the pharmacotherapy of patients of hypertension at a tertiary care hospital, Aurangabad, Maharashtra, India
}

\author{
Shruti Chandra $^{1 *}$, Amol Ubale ${ }^{2}$, Deepak Bhosle ${ }^{1}$, Deepali Jayabhaye ${ }^{1}$, Sukhmeen Kaur ${ }^{1}$
}

\begin{abstract}
${ }^{1}$ Department of Pharmacology, MGM Medical College and Research centre, Maharashtra, India

${ }^{2}$ Department of Radiation Hospital, Aurangabad, Maharashtra, India

Received: 24 April 2019 Accepted: 30 May 2019

*Correspondence to: Dr. Shruti Chandra, Email: dr.shruti1204@ gmail.com
\end{abstract} Oncology, Seth Nandlal Dhoot

Copyright: () the author(s), publisher and licensee Medip Academy. This is an openaccess article distributed under the terms of the Creative Commons Attribution NonCommercial License, which permits unrestricted noncommercial use, distribution, and reproduction in any medium, provided the original work is properly cited.

\begin{abstract}
Background: The overall prevalence for hypertension in India was estimated to be $29.8 \%$. Patient's optimal adherence with antihypertensive drug therapy is essential for preventing serious complications with hypertension over the long term. Therefore, the present study was undertaken to evaluate the prescription pattern of the drugs prescribed to hypertensive patients.

Methods: Present study was a prospective cross sectional observational study carried out in the outpatient of department of general medicine of MGM Hospital, a tertiary care teaching hospital, in Aurangabad. Prescriptions of 120 diagnosed hypertensive patients were analysed. Data was recorded as mean \pm standard deviation.

Results: The mean age of the patients was $57.13 \pm 10.94$ years with range 18-80 years. $82.5 \%$ (99) of patients were male and $17.5 \%$ (21) of patients were female. Mean duration of hypertension was $3.97 \pm 2.55$. Most of the patients $57(47.5 \%)$ were on Mono therapy significantly higher than dual therapy, triple therapy and poly therapy, $39(32.5 \%), 15(12.5 \%), 9(7.5 \%)$ respectively. Calcium channel blocker was the frequently used class of drug for monotherapy (20\%). Polytherapy was seen in $7.5 \%$ patient. Among 120 patients' only 37 patients were reported ADR. Maximum no of ADRs were reported from patients receiving ACE inhibitor.

Conclusions: This type of studies gives the base line idea of prescription pattern and ADRs of antihypertensive drugs. These help to design policy for rational use of drugs and motivation of physician for rational use of drugs.
\end{abstract}

Keywords: ADR, Hypertension, Prescription pattern

\section{INTRODUCTION}

Hypertension is a common disease which is called as a persistent elevation in blood pressure more than normal i.e. systolic BP >120 mmHg and diastolic BP >80 mmHg, increase in systolic blood pressure (SBP) of $140 \mathrm{mmHg}$ or more, and a diastolic blood pressure (DBP) of $90 \mathrm{mmHg}$ or more. Hypertension is classified into two forms according to its cause: primary or essential hypertension and secondary hypertension. ${ }^{1}$

Essential hypertension: also referred as primary or idiopathic cases where exact cause is unknown. Near about $85 \%$ of hypertensive patients suffers from essential hypertension. Secondary hypertension: caused by underling etiology such as renal like apnea, or endocrine diseases, pregnancy, smoking, stress and long-term use of alcohol etc. There are various terminologies used by physicians to describe elevated blood pressure for example malignant and transient or labile hypertension. ${ }^{2}$

In India, hypertension is a significant non-communicable disease risk attributing to $10 \%$ of all deaths. Hypertension attributes to $10 \%$ of ischemic heart disease, $21 \%$ of 
peripheral vascular disease, $24 \%$ of Acute MI, and $29 \%$ of Strokes. ${ }^{3,4}$ The overall prevalence for hypertension in India was estimated to be $29.8 \%$ according to a study by Anchala R et al. ${ }^{5}$

Until about 1950, there was no effective treatment, and the development of antihypertensive drugs has been a major therapeutic success story. Now, high blood pressure can be controlled through existing antihypertensive drug therapy by following some guidelines. The Joint National Committee (JNC-8) is considered the "gold standard" consensus guidelines for the management of hypertension. ${ }^{6}$ The other guidelines are 2017 American Hypertension Association (AHA) and the 2013 European Society of Hypertension / European Society of Cardiology (ESH) ${ }^{7,8}$ The overall principles common to these guidelines are to implement lifestyle modifications in addition to pharmacotherapy to control BP in patients with hypertension. Patient's optimal adherence with antihypertensive drug therapy is essential for preventing serious complications with hypertension over the long term. Therefore, the objective of this study was to evaluate the antihypertensive drug utilization pattern and drug-drug interactions between the drugs prescribed to hypertensive patients in a MGM super specialty hospital and teaching centre.

Therefore, all of the hypertension management guidelines, that is, eighth report of JNC 8 on Detection, Evaluation, and Treatment of High Blood Pressure (JNC-8). ${ }^{6}$ JNC 8 recommended target of diastolic $\mathrm{BP}<90 \mathrm{mmHg}$ and $\mathrm{ESH}$ 2013 recommended $<85 \mathrm{mmHg}$.

\section{METHODS}

\section{Study design}

A prospective cross sectional observational study was carried out in the outpatient of department of general medicine of MGM Hospital, a tertiary care teaching hospital, in Aurangabad. The study was started after approval from the institutional ethics committee and the hospital authorities.

\section{Selection criteria of patients}

The study population included,

- All diagnosed hypertensive patients according to JNC 8 and aged $>18$ years of either sex

- Follow up of at least 3 months.

Patients who did not receive antihypertensive treatment and Patients below 18 years of age were excluded.

Patients were diagnosed hypertensive if they had at least 2 visits with diagnosis of hypertension or they had prescription of antihypertensive drug with one recording of elevated BP or they had elevated BP on two visits. Elevated BP was defined as systolic BP >140 mmHg and
Diastolic BP (DBP) >90 mmHg. ${ }^{3}$ All basic demographic information in form of age sex, diagnosis, and duration of hypertension was recorded. Any comorbidity like nephropathy, neuropathy, Coronary Artery Disease (CAD), stroke or retinopathy was recorded.

For each prescription, drug name, number of drugs, dosage form, class and combinations of anti-hypertensive, frequency of administration and duration of treatment were retrieved. Data of antihypertensive drugs was recorded and grouped according to class of drug. Antihypertensive drugs were grouped in to seven groups Calcium channel blockers (CCB), beta blockers, diuretics, Alfa blockers, Angiotensin Convertase Enzyme Inhibitors (ACEI), Angiotensin Receptor Blockers (ARB), centrally acting drugs. Data for antihypertensive drugs was recorded in form of need of monotherapy, two drugs or three drugs therapy. Other information retrieved included the stages of hypertension at diagnosis according to the eighth report of the JNC. ${ }^{6}$ Adverse drug reactions noticed during the study were also noted down.

Data was analysed by SPSS 25 version. Data was recorded as mean \pm standard deviation. $P$ value of $<0.05$ was considered significant.

\section{RESULTS}

In this study total 120 patients were included.

\section{Age distribution of patient}

The mean age (mean \pm S.D) of the patients was $57.13 \pm 10.94$ years with range $18-80$ years and the median age was 58 years (Table 1). Test of proportion showed most of the patients were significantly higher in the age group 41-60 years.

Table 1: Distribution of age group.

\begin{tabular}{|lll|}
\hline Age group in years & No. of patients & Percent \\
\hline $18-40$ & 8 & 6.6 \\
\hline $41-60$ & 68 & 56.6 \\
\hline $61-80$ & 50 & 41.6 \\
\hline
\end{tabular}

\section{Gender distribution of patient}

The gender ratio of the patient's male: female was found to be $1.2: 1$. Out of the 120 studied patients, $82.5 \%$ (99) of patients were male and $17.5 \%$ (21) of patients were female. Test of proportion showed that the male patients were slightly more than the female patients (Table 2).

\section{Duration of hypertension}

Mean duration of hypertension (mean \pm SD) in the patients was $3.97 \pm 1.55$. Test of proportion showed $73(60.8 \%)$ patients were less than 3 years, followed by $38(31.6 \%)$ patients were between 4-6 years and least were $9(7.6 \%)$ 
were having history of $>7$ years (Table 3 ).

Table 2: Distribution of gender.

\begin{tabular}{|lll|}
\hline Gender & No. of patients & Percent \\
\hline Male & 99 & 82.5 \\
\hline Female & 21 & 17.5 \\
\hline
\end{tabular}

Table 3: Duration of hypertension.

\begin{tabular}{|lll|}
\hline Duration in years & No. of patients & Percent \\
\hline < 3 years & 73 & 60.8 \\
\hline 4-6 years & 38 & 31.6 \\
\hline$>7$ years & 9 & 7.6 \\
\hline
\end{tabular}

\section{Systolic blood pressure distribution in patients}

The mean systolic blood pressure (mean \pm S.D) of the patients was $161.67 \pm 19.43$ and the median was 152 .

Test of proportion showed most of the patients $52(43.3 \%)$ were significantly higher systolic blood pressure ranging more than $160 \mathrm{mmHg}$ (Table 4).

Table 4: Distribution of Systolic blood pressure.

\begin{tabular}{|lll|}
\hline $\begin{array}{l}\text { Systolic blood pressure } \\
\text { (mmHg) }\end{array}$ & $\begin{array}{l}\text { No. of } \\
\text { patients }\end{array}$ & Percent \\
\hline $120-139$ (Pre HTN) & 11 & 9.16 \\
\hline $140-159$ (Stage 1 HTN) & 43 & 35.8 \\
\hline $160-179$ (Stage 2 HTN) & 52 & 43.3 \\
\hline$>180$ (HTN emergency) & 14 & 11.6 \\
\hline
\end{tabular}

\section{Diastolic blood pressure distribution of patients}

The mean diastolic blood pressure (mean \pm S.D) of the patients was $98.38 \pm 13.73$.

Test of proportion showed most of the patients 51 (42.5\%) were significantly higher diastolic blood pressure ranging from 100-119 mmHg (Table 5).

Table 5: Distribution of Diastolic blood pressure.

\begin{tabular}{|lll|}
\hline $\begin{array}{l}\text { Diastolic blood } \\
\text { pressure (mmHg) }\end{array}$ & $\begin{array}{l}\text { No. of } \\
\text { patients }\end{array}$ & Percent \\
\hline $80-89$ (Pre HTN) & 13 & 10.8 \\
\hline $90-99$ (Stage 1 HTN) & 47 & 39.1 \\
\hline $100-119$ (Stage 2 HTN) & 51 & 42.5 \\
\hline$>120$ (HTN emergency) & 9 & 7.5 \\
\hline
\end{tabular}

\section{Drug therapy distribution of patients}

Test of proportion showed most of the patients 57 (47.5\%) were on Mono therapy significantly higher than dual therapy, triple therapy and poly therapy, 39 (32.5\%), 15 $(12.5 \%), 9(7.5 \%)$ respectively (Table 6).

\section{Utilization pattern of different antihypertensive drugs}

Calcium channel blocker was the frequently used class of drug for monotherapy (20\%). In dual drug therapies were $\mathrm{CCB}+\mathrm{ARB}$ accounting for $13.3 \%$, and $5.8 \%$ of patients were on triple drug therapy with $\mathrm{CCB}+\mathrm{ARB}+$ Diuretic. Polytherapy was seen in $7.5 \%$ patients.

Table 6: Distribution of drug therapy.

\begin{tabular}{|lll|}
\hline Drug Therapy & No. of patients & Percent \\
\hline Monotherapy & 57 & 47.5 \\
\hline Dual therapy & 39 & 32.5 \\
\hline Triple therapy & 15 & 12.5 \\
\hline Poly therapy & 9 & 7.5 \\
\hline
\end{tabular}

Table 7: Utilization pattern of different antihypertensive drugs.

\begin{tabular}{|lll|}
\hline Treatment & $\begin{array}{l}\text { No. of patients use } \\
\text { antihypertensive } \\
\text { drug }\end{array}$ & Percent \\
\hline Monotherapy & 24 & \\
\hline $\begin{array}{l}\text { Calcium channel } \\
\text { blocker }\end{array}$ & 11 & 20 \\
\hline ARB & 7 & 9.1 \\
\hline ACE Inhibitor & 9 & 5.8 \\
\hline Beta Blocker & 2 & 7.5 \\
\hline Alpha Blocker & 4 & 1.6 \\
\hline Diuretics & & 3.3 \\
\hline Dual therapy & 16 & 13.3 \\
\hline CCB+ARB & 9 & 7.5 \\
\hline CCB+Beta Blocker & 3 & 2.5 \\
\hline CCB+ Diuretic & 3 & 2.5 \\
\hline ARB+ Diuretic & 8 & 6.6 \\
\hline Others & & \\
\hline Triple therapy & 7 & 5.8 \\
\hline CCB+ARB+Diuretic & 7 & 4.1 \\
\hline $\begin{array}{l}\text { CCB+B } \\
\text { Blocker+Diuretic }\end{array}$ & 5 & 2.5 \\
\hline Others & 3 & 7.5 \\
\hline Polytherapy & 9 & \\
\hline & & \\
\hline
\end{tabular}

\section{Adverse drug reactions}

In the present study, causality assessment between the drug and suspected reaction was determined by using WHO-UMC Scale, Hartwig and Siegel scale and Naranjo Scale. According to Naranjo Criteria, the ADRs are analyzed on the basis of a questionnaire comprising 10 questions in which each question is given a score of +2 , $+1,0$ or -1 depending on the analysis.

When totaled if the score is $>9$ - labelled as definite ADR, if 5-8 - probable ADR, if 1-4 -possible ADR, if 0 - doubtful ADR. Among 120 patients' only 37 patients were reported ADR and males accounted for higher percent of ADRs $(67.6 \%)$ than females $(32.4 \%)$. 
Table 8: WHO causality assessment of ADRs.

\begin{tabular}{|lll|}
\hline Type of reaction & $\begin{array}{l}\text { No. of patients } \\
\text { reported ADR } \\
(37)\end{array}$ & Percent \\
\hline Certain & 3 & 8.1 \\
\hline Probable/likely & 25 & 67.5 \\
\hline Possible & 8 & 21.6 \\
\hline Unlikely & 1 & 2.7 \\
\hline Conditional/unclassified & - & - \\
\hline $\begin{array}{l}\text { Unassessable/ } \\
\text { unclassifiable }\end{array}$ & - & - \\
\hline
\end{tabular}

Causality assessment of ADRs was done using WHOUMC scale which categorizes ADRs as "certain", "probable", "possible" and "unlikely". Table 8 shows that type of reactions and their percentage are as certain $(8.1 \%)$, Probable/ Likely (67.5\%), Possible (21.6\%), and Unlikely $(2.7 \%)$.

Table 9: Severity of reported ADRs by modified Hartwig and Siegel scale.

\begin{tabular}{|lll|}
\hline Type of reaction & $\begin{array}{l}\text { No. of patients } \\
\text { reported ADR (37) }\end{array}$ & Percent \\
\hline Lethal & - & - \\
\hline Severe & 1 & 2.7 \\
\hline Moderate & 14 & 37.8 \\
\hline Mild & 22 & 59.4 \\
\hline
\end{tabular}

Table 10: Common ADR Reported.

\begin{tabular}{|llcc|}
\hline Class of drugs & Adverse events experienced & No of patients & $\%$ \\
\hline CCB & Pedal edema, giddiness, headache, abdominal pain, bradycardia & 10 & 27.0 \\
\hline ARB & $\begin{array}{l}\text { Anxiety, Nausea and Vomiting, Headache, Abdominal pain, } \\
\text { Restlessness, Itching and inflammatory swelling }\end{array}$ & 7 & 18.9 \\
\hline ACE Inhibitor & $\begin{array}{l}\text { Dry cough, dizziness, headache, drowsiness, diarrhea, hypotension, } \\
\text { weakness, cough, rash, metallic or salty taste. }\end{array}$ & 12 & 32.4 \\
\hline Beta Blocker & $\begin{array}{l}\text { Constipation, nausea and vomiting, headache, hypoglycemia, postural } \\
\text { hypotension }\end{array}$ & 3 & 8.1 \\
\hline Diuretics & Hypotension, muscle cramps, headache vertigo, pain in legs, dysuria & 2 & 5.4 \\
\hline Other & Skin reaction & 3 & 8.1 \\
\hline
\end{tabular}

\section{Adverse drug reactions and therapeutics class of suspected medication}

Total 37 patients were reported ADR. $32.4 \%$ patients were on ACE inhibitors. $27 \%$ patients receiving Calcium channel blocker reported side effect.

\section{DISCUSSION}

Hypertension is a very common medical condition worldwide and is the principal cause of stroke, is a major risk factor for coronary artery disease and its complications. It is a major contributor to cardiac failure, renal insufficiency, and dissecting aortic aneurysm. ${ }^{9-12}$ Choice of an antihypertensive drug should be driven by likely benefit in an individual patient, taking into account concomitant diseases such as diabetes mellitus, problematic adverse effects of specific drugs, and cost. ${ }^{13}$ The overall goal of treating hypertension is to reduce hypertension associated morbidity and mortality.

In this study, the maximum number of patients, were from the age group of 41-60 (56.6\%) years followed by $61-80$ $(41.6 \%)$ and lest number in $18-40(6.6 \%)$ years of age of patients are from this age group Whereas, total 120 patients were there, including 99 (82.5) males and 21
(17.5) females (Table 2) and showing a predominance of male population. The hypothetical cause of higher number of male patients is elevated levels of androgen such as testosterone as they play a role in elevation of blood pressure. ${ }^{14} \mathrm{~A}$ similar study was also conducted by Amit sharma et al, which is supporting this study. ${ }^{15}$

Furthermore, maximum number of patients was seen in less than 3 years duration of hypertension followed by 4-6 years of duration and minimum number of patients was seen in more than 7 years of duration. In addition, systolic blood pressure, maximum number of patients in stage 2, followed by stage 1 and hypertensive emergency and lowest number in pre-stage hypertension. On the other hand, diastolic blood pressure, maximum number of patients in stage 2 followed by stage 1 and hypertensive emergency and lowest number in pre-stage hypertension.

In this study, maximum number of patients were on Single drug therapy $(47.5 \%)$, followed by $47.5 \%$ of patients on dual drug therapies, and $12.5 \%$ of patients were on triple drug therapy (Table 6) for treatment of hypertension. Calcium channel blocker was the frequently used drug for monotherapy (20\%), and the most commonly used drugs in dual drug therapies were $\mathrm{CCB}+\mathrm{ARB}$ accounting for $13.3 \%$, and $5.8 \%$ of patients were on triple drug therapy 
with $\mathrm{CCB}+\mathrm{ARB}+$ Diuretic. In a study by Mohd $\mathrm{AH}$ et al, the most commonly prescribed antihypertensive among elderly patients was Amlodipine. ${ }^{16}$ This is also in consonance with the recommendations of the JNC on Prevention, Detection, Evaluation, and Treatment of high blood pressure guidelines which state that low dose of different classes of antihypertensive drugs is more beneficial than a high dose of one. ${ }^{6}$

According to WHO-UMC Scale maximum number of ADRs in probable class followed by possible, unlikely and certain class. Moreover, as per the modified Hartwig and Siegel's scale maximum number of ADRs was mild category and lowest in sever type of reaction was observed in this study. No ADRs were found in lethal type of reaction. These findings were consistent with the literature reported by Ganachari et al, and Singh et al, Total 37 patients were reported ADR. ${ }^{17,18} 32.4 \%$ patients were on ACE inhibitors. $27 \%$ patients receiving Calcium channel blocker reported side effect.

\section{CONCLUSION}

The knowledge and prescription of drug was concluding to be the base line idea of ADRs of antihypertensive drugs in hypertensive patients visiting OPD of tertiary teaching care hospital in India. In this study, Authors can't say that all of the prescriptions found were rational; furthermore, more changes are needed to be done in prescription of antihypertensive drugs are needed in drug prescribing practices in hypertensive patients. Patients are needed to provide information and proper counselling regarding the ADRs of drugs; this would refine the quality of life. Keeping in mind the limitations of the current study, less time period and lesser no. of subjects included. However, since this study is mainly limited to pattern of drug usage in hypertensive population in a tertiary care hospital, care must be exercised in generalizing the study results to prescribing pattern of the whole region.

\section{ACKNOWLEDGEMENTS}

Authors are thankful to staff of Medicine department for their co-operation during the study.

Funding: No funding sources Conflict of interest: None declared

Ethical approval: The study was approved by the Institutional Ethics Committee

\section{REFERENCES}

1. Rang HP, Dale MM, Ritter JM, Flower RJ, Henderson G. The Vascular System, 7th, Churchill LivingstoneElsevier;2012:277-283.

2. Walker BR, Colledge NR, Ralston SH, Penman ID. Hypertension, Davidson's Principles and Practice of Medicine. $21^{\text {st }}$ Edition, Churchill LivingstoneElsevier;2010:606-610.
3. Singh RB, Suh IL, Singh VP, Chaithiraphan S, Laothavorn P, Sy RG, et al. Hypertension and stroke in Asia: prevalence, control and strategies in developing countries for prevention. J Hum Hypertens. 2000 Oct;14(10):749-63.

4. Gupta R, Gupta VP. Hypertension epidemiology in India: Lessons from Jaipur Heart Watch. Curr Sci. 2009;97(3):349-55.

5. Anchala R, Kannuri NK, Pant H, Khan H, Franco OH, Di Angelantonio E, et al. Hypertension in India: a systematic review and meta-analysis of prevalence, awareness, and control of hypertension. J Hypertens. 2014;32(6):1170-7.

6. James PA, Oparil S, Carter BL, Cushman WC, Himmelfarb CD, Handler J, et al. Evidence-based guideline for the management of high blood pressure in adults. Report from the panel members appointed to the eighth joint national committee (JNC 8). JAMA. 2014;311(5):507-20.

7. Whelton PK, Carey RM, Aronow WS, Casey DE, Collins KJ, Himmelfarb CD, et al. 2017 ACC/AHA/AAPA/ABC/ACPM/AGS/APhA/ASH/A SPC/NMA/PCNA guideline for the prevention, detection, evaluation, and management of high blood pressure in adults: a report of the American College of Cardiology/American Heart Association Task Force on Clinical Practice Guidelines. J Am Coll Cardiol. 2018;71(19):e127-248.

8. Williams B, Mancia G, Spiering W, Agabiti Rosei E, Azizi M, Burnier M, et al. 2018 ESC/ESH Guidelines for the management of arterial hypertension. Eur Heart J. 2018 Aug 25;39(33):3021-104.

9. Chobanian AV, Bakris JL, Black HR, Cushman WC, Green LA. Seventh report of the joint national committee on prevention, detection, evaluation and treatment of high blood pressure. Hypertension. 2003;42(6):1206-52.

10. Yusuff KB, Balogun OB. Physicians' prescribing of antihypertensive combinations in a tertiary care setting in southwestern Nigeria. J Pharm Pharm Sci. $2005 ; 8(2): 235-42$.

11. Tiwari H, Kumar A, Kulakarni SK. Prescription monitoring of anti-hypertensive drug utilization at the panjab university health centre in India. Singapore Med J. 2004; 45(3):117-20.

12. Kapoor K, Raina RK, Kapoor S. Drug prescribing pattern in a teaching hospital. Indian $\mathrm{J}$ Pharmacol. 1985;17(1):168.

13. Pradhan SC, Shewade DG, Shashindaran CH, Bapna JS. Drug Utilization studies. National Med J India. 1988;1(4):185-9.

14. Tasneem S, Fouzia N. Drug utilization study in ischemic heart diseases associated with diabetes and hypertension. Int J Pharm Bio Sci. 2010;1(3):1-4.

15. Sharma A, Badwal TK, Gupta V, Rathore MS, Chhabra M, Gaur A. Drug Utilization Study on Hypertensive Patients and Assessment of Medication Adherence to Jnc-8 Guidelines in North Indian Tertiary Care Hospital: A Cross-Sectional Study. Adv Res Gastroentero Hepatol. 2018;9(1):555751. 
16. Mohd AH, Mateti UV, Konuru V, Parmar MY, Kunduru BR. A study on prescribing patterns of antihypertensives in geriatric patients. Perspect Clin Res. 2012;3(4):139-42.

17. Ganachari MS, Wadhwa T, Walli S, Disha AK, Aggarwal A. Trigger tools for monitoring and reporting of adverse drug reactions: A Scientific tool for efficient reporting. Open Access Scientific Rep. 2013;2(4):1-5.

18. Singh H, Kumar BN, Sinha T, Dulhani N. The incidence and nature of drug-related hospital admission: A 6-month observational study in a tertiary health care hospital. J Pharmacol Pharmacother. 2011;2(1):17-20.

Cite this article as: Chandra $\mathrm{S}$, Ubale $\mathrm{A}$, Bhosle D, Jayabhaye D, Kaur S. A study of prescription pattern of the pharmacotherapy of patients of hypertension at a tertiary care hospital, Aurangabad, Maharashtra, India. Int J Basic Clin Pharmacol 2019;8:1599-604. 